\title{
ADSORÇÃO APLICADA AO TRATAMENTO DE EFLUENTES DE TINGIMENTO DE CURTUMES
}

\author{
C.S. GOMES ${ }^{1}$, A. C. F. TRUCOLO ${ }^{1}$, W. VEBER ${ }^{1}$, J.S. PICCIN ${ }^{1,2}$ e M. GUTTERRES ${ }^{1}$ \\ ${ }^{1}$ Universidade Federal do Rio Grande do Sul (UFRGS), Programa de Pós-graduação em \\ Engenharia Química, Laboratório de Estudos em Couro e Meio Ambiente \\ (LACOURO). \\ ${ }^{2}$ Faculdade de Engenharia e Arquitetura, Curso de Engenharia de Alimentos, \\ Universidade de Passo Fundo. \\ carolina@enq.ufrgs.br
}

\begin{abstract}
RESUMO - Em curtumes, na etapa de tingimento, é necessário fazer uma ou várias adições de corantes para que a textura fibrosa de couro seja tingida em profundidade, com intensidade e uniformidade na superfície. Esta etapa do processamento do couro resulta em efluentes coloridos residuais. A presença de corantes dificulta o tratamento dos efluentes por métodos convencionais e sua reutilização no processo produtivo, pois causaria tingimento de uma nova partida com cor indesejada. A adsorção é uma operação de tratamento avançada para aumentar a qualidade final ou viabilizar o reuso de águas. Uma de suas maiores vantagens é a possibilidade de uso de materiais de baixo custo no tratamento de efluentes, e, neste caso foram utilizados como adsorventes, resíduos sólidos de curtumes, farelos de couro curtido ao cromo, para tratar efluentes de tingimento do couro. Os experimentos de adsorção foram realizados em fulões em escala laboratorial, chegando a remover $95 \%$ de corantes em $\mathrm{pH} 3,0$ e temperatura de $65^{\circ} \mathrm{C}$.
\end{abstract}

\section{INTRODUÇÃO}

A indústria de couros vem crescendo de maneira notável nas últimas décadas, principalmente em países em desenvolvimento. Segundo a ABQTIC (2013), a produção mundial de couros bovinos aumentou entre 2000 e 2012, de 290 para quase 325 milhões de couros e, neste mesmo período, o rebanho de bovinos cresceu quase 9\%. Enquanto isso, a produção de artigos manufaturados de couro, como calçados e acessórios automobilísticos, também aumentou, justificando o crescimento da indústria coureira. A indústria brasileira de couro possui cerca de 750 curtumes, sendo que quase $75 \%$ destes curtumes se localizam nas regiões sul e sudeste. O Rio Grande do Sul é o maior produtor de couros do país, com quase $35 \%$ da produção nacional. Além disso, o mercado coureiro obteve um saldo com importações e exportações de dois bilhões de dólares no ano de 2012, mostrando sua grande importância para a economia brasileira (ABQTIC, 2013).

Segundo GUTTERRES et al. (2008), esta indústria utiliza grandes quantidades de água, já que a maioria dos seus processos ocorre em meio aquoso e esta água deve estar presente em grandes quantidades. Estima-se que em um curtume com boas práticas ambientais são necessários de 12 a $37 \mathrm{~m}^{3}$ de água para cada tonelada de pele salgada transformada em couro (IULTCS, 2012). Os efluentes oriundos dos curtumes são tratados em estações de tratamento que, normalmente, compreendem as fases de prétratamento, tratamento mecânico e físico-químico, tratamento biológico e tratamento do 
lodo gerado. Os tratamentos avançados de efluentes podem permitir o reuso da água, porém ainda não são introduzidos no processo (GUTTERRES et al., 2008; COOPER et al., 2011).

A geração de resíduos sólidos em diversas etapas do processo produtivo do couro pode chegar até $700 \mathrm{~kg}$ por tonelada de pele salgada (GANEM, 2007). Dentre estes resíduos, os mais problemáticos são os resíduos de couro curtido ao cromo, já que são considerados perigosos e devem ser enviados para aterros especiais. Por isso, estudos que buscam reaproveitar estes resíduos são tão importantes.

A adsorção é um dos métodos mais populares para tratamento de águas residuais contaminadas com metais pesados, aromáticos e moléculas de coloração, já que seu projeto adequado irá gerar efluentes tratados de alta qualidade (CRINI, 2005). Em geral, a adsorção ocorre porque os átomos de uma superfície não possuem as forças de atração balanceadas. Desta forma, as forças de atração devem ser compensadas, fazendo com que as moléculas presentes em uma fase fluida sejam adsorvidas na fase sólida (CIOLA, 1981).

Existe um grande interesse em estudar a adsorção como tratamento alternativo para a remoção dos corantes presentes nos efluentes de tingimento, utilizado resíduos de couro gerados no próprio curtume. Tudo isso visando a utilização deste processo na indústria.

\section{MATERIAIS E MÉTODOS}

\subsection{Material}

O resíduo de couro curtido ao cromo utilizado nos experimentos foi obtido em um curtume local (Portão, RS) e é proveniente da etapa de rebaixamento para ajuste da espessura do couro wet-blue antes de iniciar o acabamento molhado, sendo gerado na forma de serragem ou farelo. Esse resíduo foi seco em estufa a $60{ }^{\circ} \mathrm{C}$ e vácuo de -68 $\mathrm{kPa}$ durante $48 \mathrm{~h}$. Após seco, os resíduos foram moídos em moinho de facas e separados entre peneiras de 6, 8, 12 e 42 mesh para obter tamanhos médios de partícula de 0,9; 1,9 e 2,9 mm. Tamanhos de partícula menores seriam inadequados para o processo já que sua separação do efluente tratado seria mais difícil e sua preparação requereria um gasto energético maior.

O corante utilizado foi fornecido pela Divisão de Couros da Empresa Lanxess. Este corante foi o Vermelho Ácido 357, de nome comercial Baygenal Vermelho GT, um corante diazo-dissulfonado cromo complexado de fórmula molecular $\mathrm{C}_{32} \mathrm{H}_{20} \mathrm{CrN}_{10} \mathrm{O}_{14} \mathrm{~S}_{2}$.3Na, caráter aniônico, peso molecular 956,7 $\mathrm{mg} \mathrm{g}^{-1}$ pureza de $55 \%$ e número CAS 57674-14-3.

\section{2 Águas Residuárias}

Para obter efluentes líquidos com características similares ao que é gerado na operação de acabamento molhado de couro na indústria, esta etapa foi reproduzida em escala laboratorial. Para isso, um couro wet-blue curtido ao cromo foi submetido a uma formulação completa de acabamento molhado envolvendo as etapas de remolho, desacidulação, lavagem, recurtimento, engraxe, tingimento, lavagem, remonte e lavagem nesta ordem.

Os efluentes gerados em cada etapa foram coletados e misturados a fim de gerar duas amostras compostas. A amostra composta 1(AC1) contém os efluentes de todas as 
etapas, logo tem uma concentração de corante mais baixa (CB). Já a amostra composta 2 (AC2) é formada apenas pelos efluentes das etapas após a adição de corante, ou seja, a etapa de tingimento em diante e por isso tem uma concentração mais alta (CA). A mistura de AC1 e AC2 gera um efluente de concentração média (CM). Estas amostras foram armazenadas em geladeira para posterior uso nos ensaios.

\subsection{Ensaios de Adsorção}

Os ensaios de adsorção foram realizados em fulões em escala laboratorial para que as condições da indústria possam ser mais bem reproduzidas. Em cada ensaio um litro de água residuária com concentração conhecida foi utilizada. Para seu ajuste de $\mathrm{pH}$ foram utilizados ácido fórmico e hidróxido de sódio. $\mathrm{O} \mathrm{pH}$ de uma massa de adsorvente conhecida também foi ajustado adicionado $300 \mathrm{ml}$ de solução tampão de Mcllvaine, sendo essa mistura deixada em contato por 10 minutos antes da adição da água residuária para que ocorresse o equilíbrio do $\mathrm{pH}$. Depois disso a água residuária e o adsorvente foram misturados no fulão, operando à temperatura e agitação definidas. Alíquotas foram retiradas ao longo do experimento em intervalos de tempos préestabelecidos.

As leituras de concentração de corante na fase líquida foram realizadas em um espectrofotômetro UV-Visível (PG Instruments, modelo T80) a $\lambda_{\text {máx }} 494 \mathrm{~nm}$. Os valores obtidos foram utilizados para a determinação da capacidade de adsorção e plotados contra o tempo com a finalidade de se obter parâmetros cinéticos.

A capacidade de adsorção é um parâmetro utilizado na interpretação de todos os dados obtidos nas cinéticas de adsorção. É definida como a quantidade de adsorbato adsorvido por unidade de massa de adsorvente, ou seja, a quantidade de corante adsorvido por unidade de massa de couro, e é representada pela Equação 2.1.

$$
\mathrm{q}=\frac{\mathrm{Co}-\mathrm{C}_{\mathrm{t}}}{\mathrm{m}} \mathrm{V}
$$

Sendo a concentração de corante, no início do experimento, representada por $\mathrm{C}_{\mathrm{o}}(\mathrm{mg}$ $\left.\mathrm{l}^{-1}\right)$, a concentração de corante num dado momento é representada por $\mathrm{C}_{t}\left(\mathrm{mg} \mathrm{l}^{-1}\right)$, a massa do resíduo de couro por m (g) e o volume total da solução por V (l).

\subsection{Delineamento Experimental}

Os experimentos de adsorção foram realizados de acordo com as técnicas de planejamento experimental (BOX et al., 1978), as variáveis de interesse foram a Concentração de adsorvente (W), o pH, a Temperatura (T), a Concentração de corante (C), a Velocidade de Rotação (Rot), o Tempo (t) e o Diâmetro de partícula (Dp). E para ter um entendimento completo do sistema, precisou-se estudar o efeito dessas variáveis em duas respostas, sendo elas a capacidade de adsorção no equilíbrio $\left(\mathrm{q}_{\mathrm{e}}\right)$ e a Remoção de corante (R).

Para que o estudo dos efeitos dos fatores sobre as respostas fosse feito de forma coerente e organizada, de forma a gerar os melhores resultados possíveis foi proposto um planejamento experimental do tipo Plackett e Burman, muito útil quando se tem muitos fatores já que com ele é possível entender quais delas realmente afetam o sistema. A Tabela 2.1 apresenta os níveis codificados e os respectivos valores reais para os fatores estudados no planejamento. 
Tabela 2.1 - Fatores e seus níveis no planejamento experimental

\begin{tabular}{c|ccc}
\hline Fator / Nível & -1 & 0 & +1 \\
\hline $\mathrm{W}\left(\mathrm{g} \mathrm{l}^{-1}\right)$ & 5 & 10 & 15 \\
$\mathrm{pH}$ & 3 & 4,5 & 6 \\
$\mathrm{~T}\left({ }^{\circ} \mathrm{C}\right)$ & 25 & 45 & 65 \\
$\mathrm{C}$ & $\mathrm{CB}$ & $\mathrm{CM}$ & $\mathrm{CA}$ \\
Rot (rpm) & 20 & 35 & 50 \\
$\mathrm{t}(\mathrm{min})$ & 60 & 105 & 150 \\
$\mathrm{Dp}(\mathrm{mm})$ & 0,9 & 1,9 & 2,9 \\
\hline
\end{tabular}

Seguindo este planejamento foram realizados dezesseis ensaios de adsorção, sendo quatro deles o ponto central.

\section{RESULTADOS E DISCUSSÃO}

Foram avaliadas as cinéticas de adsorção de corantes das águas residuárias pelos resíduos de couro para todos os experimentos do planejamento, sendo que foi feita uma média dos quatro ensaios do ponto central (PC). O comportamento das cinéticas obtidas é apresentado na Figura 3.1.

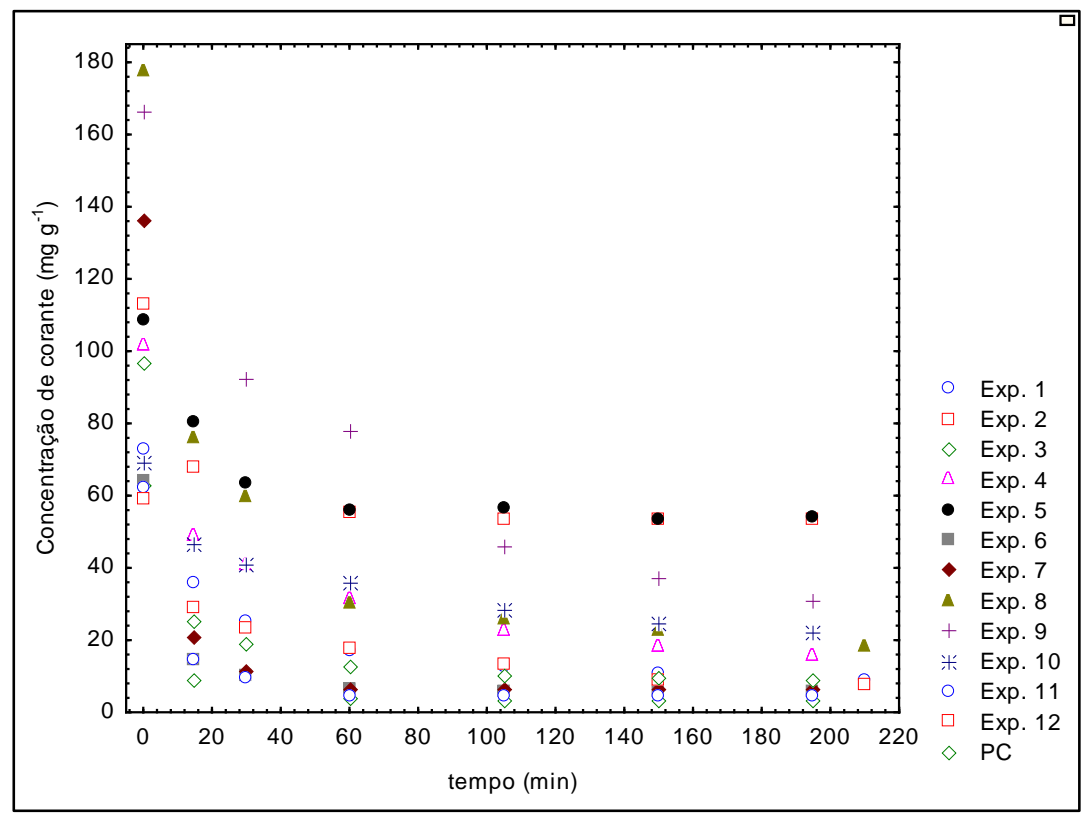

Figura 3.1: Cinéticas de adsorção de corantes das águas residuárias pelos resíduos de couro para todos os experimentos do planejamento

Nesta figura verifica-se que o equilíbrio já é alcançado na maioria dos experimentos em menos de 60 minutos. Esta é uma observação muito importante já que indica que longos tempos de adsorção não são necessários para obter bons resultados.

Para entender os mecanismos envolvidos na adsorção os dados obtidos foram analisados conforme as cinéticas de pseudo-primeira e pseudo-segunda ordem. O 
modelo que apresentou o melhor ajuste com os dados experimentais foi o de pseudosegunda ordem o que sugere que a difusão das moléculas de corante para o interior do couro é o passo restritivo à velocidade de adsorção que por sua vez, é de natureza química.

Foi gerado um planejamento experimental do tipo Plackett e Burman para 11 parâmetros (sendo quatro deles destinados aos graus de liberdade para o cálculo dos resíduos) e com ponto central. Este planejamento é do tipo ortogonal, o que permite que os efeitos principais de cada variável sejam determinados individualmente, admitindo-se que os efeitos de interação sejam desprezíveis.

A Tabela 3.1 apresenta os fatores do planejamento experimental, com seus níveis reais e codificados, e os valores das respostas estudadas observados em cada experimento, sendo elas a capacidade de adsorção no equilíbrio segundo o modelo de pseudo-segunda ordem $\left(\mathrm{q}_{\mathrm{e}}\right)$ e a percentagem de remoção de corante $(\mathrm{R})$.

Tabela 3.1 - Fatores e seus níveis no planejamento experimental Plackett e Burman e valores observados para as respostas estudadas

\begin{tabular}{c|ccccccc|cc}
\hline Exp. & $\begin{array}{c}\mathrm{W} \\
\left(\mathrm{g}^{-1}\right)\end{array}$ & $\mathrm{pH}$ & $\mathrm{T}\left({ }^{\circ} \mathrm{C}\right)$ & $\mathrm{C}$ & $\begin{array}{c}\text { Rot } \\
(\mathrm{rpm})\end{array}$ & $\mathrm{t}(\mathrm{min})$ & $\begin{array}{c}\mathrm{Dp} \\
(\mathrm{mm})\end{array}$ & $\begin{array}{c}\mathrm{q}_{\mathrm{e}} \\
\left(\mathrm{mg} \mathrm{g}^{-1}\right)\end{array}$ & $\begin{array}{c}\mathrm{R} \\
(\%)\end{array}$ \\
\hline 1 & $15(+1)$ & $6(+1)$ & $25(-1)$ & $\mathrm{CB}(-1)$ & $20(-1)$ & $150(+1)$ & $2,9(+1)$ & 6,99 & 85,33 \\
2 & $5(-1)$ & $6(+1)$ & $65(+1)$ & $\mathrm{CA}(+1)$ & $20(-1)$ & $60(-1)$ & $2,9(+1)$ & 19,42 & 52,66 \\
3 & $15(+1)$ & $3(-1)$ & $65(+1)$ & $\mathrm{CB}(-1)$ & $20(-1)$ & $60(-1)$ & $2,9(+1)$ & 6,17 & 94,58 \\
4 & $15(+1)$ & $6(+1)$ & $25(-1)$ & $\mathrm{CA}(+1)$ & $50(+1)$ & $60(-1)$ & $0,9(-1)$ & 8,04 & 68,98 \\
5 & $5(-1)$ & $6(+1)$ & $65(+1)$ & $\mathrm{CA}(+1)$ & $20(-1)$ & $150(+1)$ & $0,9(-1)$ & 22,32 & 48,27 \\
6 & $15(+1)$ & $6(+1)$ & $65(+1)$ & $\mathrm{CB}(-1)$ & $50(+1)$ & $60(-1)$ & $0,9(-1)$ & 6,32 & 90,22 \\
7 & $15(+1)$ & $3(-1)$ & $65(+1)$ & $\mathrm{CA}(+1)$ & $50(+1)$ & $150(+1)$ & $2,9(+1)$ & 13,71 & 95,45 \\
8 & $15(+1)$ & $3(-1)$ & $25(-1)$ & $\mathrm{CA}(+1)$ & $20(-1)$ & $150(+1)$ & $0,9(-1)$ & 17,40 & 83,07 \\
9 & $5(-1)$ & $3(-1)$ & $25(-1)$ & $\mathrm{CA}(+1)$ & $50(+1)$ & $60(-1)$ & $2,9(+1)$ & 50,74 & 77,76 \\
10 & $5(-1)$ & $6(+1)$ & $25(-1)$ & $\mathrm{CB}(-1)$ & $50(+1)$ & $150(+1)$ & $2,9(+1)$ & 14,92 & 63,98 \\
11 & $5(-1)$ & $3(-1)$ & $65(+1)$ & $\mathrm{CB}(-1)$ & $50(+1)$ & $150(+1)$ & $0,9(-1)$ & 19,15 & 92,74 \\
12 & $5(-1)$ & $3(-1)$ & $25(-1)$ & $\mathrm{CB}(-1)$ & $20(-1)$ & $60(-1)$ & $0,9(-1)$ & 14,47 & 70,49 \\
13 & $10(0)$ & $4,5(0)$ & $0(45)$ & $\mathrm{CM}(0)$ & $35(0)$ & $105(0)$ & $1,9(0)$ & 14,17 & 88,42 \\
14 & $10(0)$ & $4,5(0)$ & $0(45)$ & $\mathrm{CM}(0)$ & $35(0)$ & $105(0)$ & $1,9(0)$ & 14,68 & 89,14 \\
15 & $10(0)$ & $4,5(0)$ & $0(45)$ & $\mathrm{CM}(0)$ & $35(0)$ & $105(0)$ & $1,9(0)$ & 14,39 & 89,23 \\
16 & $10(0)$ & $4,5(0)$ & $0(45)$ & $\mathrm{CM}(0)$ & $35(0)$ & $105(0)$ & $1,9(0)$ & 13,75 & 89,27 \\
\hline
\end{tabular}

A Figura 3.2 apresenta os gráficos de Pareto dos efeitos padronizados para as respostas $\mathrm{q}_{\mathrm{e}} \mathrm{e} \mathrm{R}$. Estes diagramas apresentam de forma rápida e clara os efeitos que são estatisticamente importantes, nestes gráficos eles foram apresentados com asteriscos conforme a legenda do gráfico. 
a)

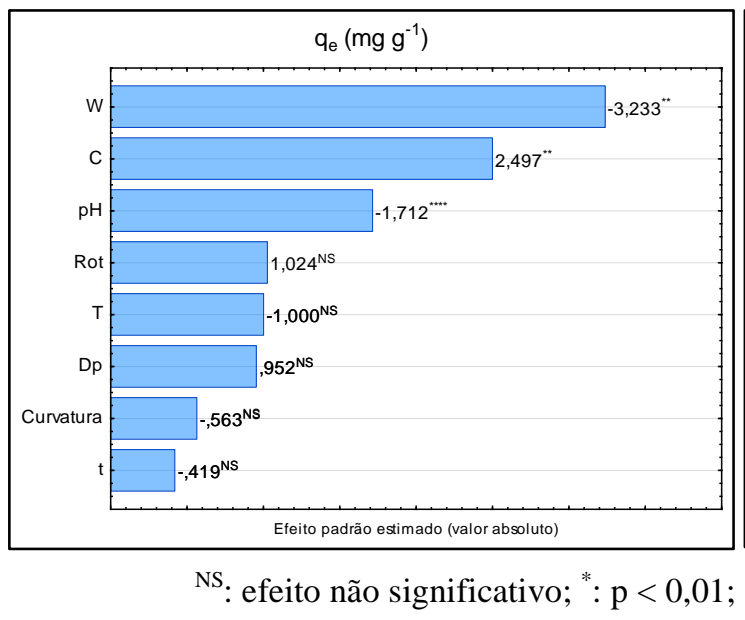

b)

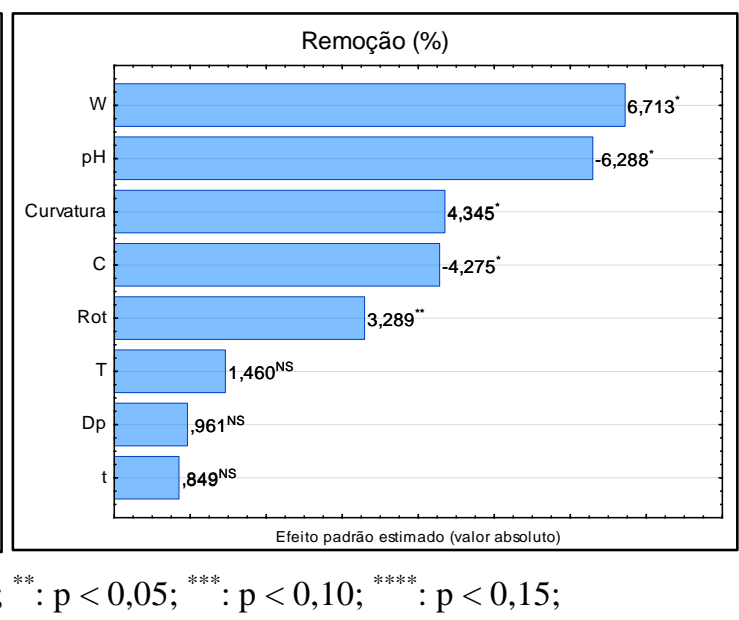

Figura 3.2 - Gráfico de Pareto dos efeitos padronizados da capacidade de adsorção no equilíbrio (a) e remoção (b) do corante Vermelho 357 em efluentes de tingimento do couro

Para a capacidade de adsorção no equilíbrio o gráfico indica que foram significativos, em ordem decrescente, apenas a concentração de adsorvente, a concentração de corante e o pH. Os fatores W e C estão relacionados com a força motriz que causa a transferência de massa entre as fases. A concentração de adsorvente tem efeito negativo, pois com o aumento do número de sítios disponíveis para a adsorção ocorre uma redução da concentração de corante na fase líquida, e com isso a redução dessa força motriz. Já a concentração de corante tem efeito positivo porque quanto maior sua concentração maior será a diferença de concentrações na fase fluida e no adsorvente, aumentando a força motriz (PICCIN et al., 2011). Com relação ao pH, este fator teve um efeito negativo na resposta, isso ocorre porque quando o $\mathrm{pH}$ é reduzido acontece a protonação dos grupamentos amina do couro para a forma $\mathrm{NH}^{3+}$. O corante Vermelho 357 tem caráter aniônico, logo ele é atraído para a superfície do adsorvente, aumentando a capacidade de adsorção.

Com relação à remoção de corante dos efluentes os fatores significativos, em ordem decrescente, foram a concentração de adsorvente, $\mathrm{pH}$, concentração de corante e a velocidade rotação. A concentração de adsorvente é significativa de forma positiva, ou seja, quanto maior a quantidade de adsorvente presente no meio maior será a remoção. Isso se deve ao fato de que quanto maior a quantidade de adsorvente maior será a quantidade de sítios ativos disponíveis para fazer a adsorção. A velocidade de rotação também tem efeito positivo, provavelmente porque com o aumento da velocidade aumenta a movimentação das moléculas, facilitando a adsorção.

Da mesma forma que no caso da resposta $\mathrm{q}_{\mathrm{e}}$, o pH é significativo de forma negativa na remoção de corante. Os mesmos motivos se aplicam neste caso, as interações entre a superfície protonada do couro e o corante de característica aniônica são favorecidas. A concentração de adsorvente também tem efeito negativo, isso provavelmente se deve ao fato de que uma baixa concentração de corante demora mais para saturar o adsorvente disponível, sendo possível remover uma maior percentagem de corante.

Outra informação importante que pode ser vista na Figura 3.2 (b) é que ela indica que existe curvatura no modelo estatístico, já que o efeito curvatura foi significativo de 
forma positiva. Isto indica que existe um ponto de remoção máxima entre os pontos de máximo e mínimo das variáveis estudadas.

Os fatores temperatura, diâmetro de partícula e tempo não foram significativos para as duas respostas. A variação de temperatura entre temperaturas médias e altas não foi significativa, em estudos anteriores o mesmo foi visto por PICCIN et al. (2013) já que as isotermas de adsorção do corante Vermelho 357 por resíduos de couro curtido ao cromo em diferentes temperaturas $\left(15^{\circ} \mathrm{C}, 25^{\circ} \mathrm{C}, 35^{\circ} \mathrm{C}\right.$ e $\left.45^{\circ} \mathrm{C}\right)$ não apresentarem diferenças significativas. O tempo não foi significativo já que nestes experimentos não foi necessário um longo período de tempo para que o sistema alcançasse o equilíbrio, fazendo com que longos tempos de adsorção sejam desnecessários. Esta informação confirma o que já foi discutido anteriormente na Figura 3.1. Já a diferença entre os diâmetros de partícula no intervalo estudado não foi significativa.

\section{CONCLUSÕES}

Os resíduos de couro curtido ao cromo mostraram-se eficientes na remoção do corante Vermelho 357 das águas residuárias da etapa de acabamento molhado do couro, podendo alcançar remoções de corante superiores a 95\%.

Os resultados obtidos mostram que aumentando a concentração de adsorvente aumenta o número de sítios onde a adsorção pode ser realizada. Isso faz com que aumente a remoção do corante da solução, porém a capacidade de adsorção no equilíbrio diminui nestas condições, pois a diminuição da concentração de corante na fase líquida reduz a força motriz que causa a transferência entre as fases.

A redução do $\mathrm{pH}$ aumenta a atração do corante pelas moléculas de couro aumentando a capacidade de adsorção no equilíbrio e também a remoção.

O aumento na concentração de corante aumenta a força motriz que causa a transferência de massas aumentando a capacidade de adsorção no equilíbrio, mas no caso da remoção esse aumento é prejudicial já que o adsorvente é saturado e os níveis de remoção ainda são baixos.

Uma maior velocidade de rotação aumenta a movimentação das moléculas aumentando também a remoção do corante dos efluentes.

Além destes fatores a temperatura, o diâmetro de partículas e o tempo não causaram impactos nos valores observados de capacidade de adsorção no equilíbrio e remoção de corante.

\section{AGRADECIMENTOS}

Os autores agradecem ao CNPq (Edital UNIVERSAL - MCTI/CNPq No 14/2013) pelo apoio financeiro, a CAPES pela concessão de bolsa de pesquisa e à empresa Lanxess pelo apoio técnico. 


\section{REFERÊNCIAS BIBLIOGRÁFICAS}

ABQTIC. Guia brasileiro do couro. 2013.

BOX, E. G. P.; HUNTER, W. G., HUNTER, J. S. Statistics for Experiments: An Introduction to Designs, Data Analysis and Model Building. Nova York: Editora Wiley, 1978.

CIOLA, R. Fundamentos da Catálise. São Paulo: Editora Moderna, 1981.

COOPER, M.; GUTTERRES, M.; MARCÍLIO, N. Environmental Developments and Researches in Brazilian Leather Sector. Journal of the Society of Leather Technologists and Chemists, v. 95, p. 243-249, 2011.

CRINI, G. Recent developments in polysaccharide-based materials used as adsorbents in wastewater treatment. Progress in Polymer Science, v. 30, p. 38-70, 2005.

IULTCS. IUE 6 - Typical pollution values related to conventional tannery processes. <http://www.iultcs.org/environment.asp>, april/2012.

GANEM, R. S. Curtumes aspectos ambientais. Biblioteca Digital da Câmara dos Deputados, Brasília, 2007.

GUTTERRES, M.; PASSOS, J. B.; AQUIM, P. M.; SEVERO, L. S.; TRIERWEILER, J. O. Reduction of water demand and treatment cost in tanneries through reuse technique. Journal of the American Leather Chemists Association, v. 103, p. 138-143, 2008.

PICCIN, J. S.; FERIS, L. A.; COOPER, M.; GUTTERRES, M. Dye adsorption by leather waste: mechanism diffusion, nature studies, and thermodynamic data. Journal Chemical Engineering Data, v. 58 (4), p. 873-882, 2013.

PICCIN, J. S.; DOTTO, G. L.; VIEIRA, M. L. G.; PINTO, L. A. A. Kinetics and Mechanism of the Food Dye FD\&C Red 40 Adsorption onto Chitosan. Journal of Chemical \& Engineering Data v. 56, p. 3759-3765, 2011. 